\title{
Types of Vertical Smart Farms and Awareness of their use in Korean Cities Types and Feasibility Analysis of Vertical Smart Farms in Korean Cities
}

\author{
Han Kyul Heo and Eunseok Lee* \\ Associate Research Fellow, Architecture \& Urban Research Institute, Sejong 30103, Korea
}

\section{ABSTRACT}

Background and objective: Vertical smart farm (VSF) is an alternative that contributes to solving various problems such as climate change and food shortage. This study focused on the types and awareness of VSF to introduce and diffuse VSF. We aimed to investigate the types of VSF and citizens' awareness on VSF. We analyzed 1) where the smart farm technology could be implemented on a building; 2) what citizens think about VSF; and 3) suggested what is most necessary for the introduction and diffusion of VSF in the future based on citizens' perception.

Methods: VSF types were investigated through case studies on VSF in Korea and overseas. Citizens' perception on VSF was investigated through a questionnaire survey. A statistical analysis was conducted with the survey results for implications of the introduction and diffusion of VSF.

Results: Four types of VSF were derived: rooftop farms, facade farms, indoor farms, and farms using the whole building. The survey showed that $29.2 \%, 27.8 \%$, and $22.2 \%$ of respondents knew well about urban agriculture, smart farms, and vertical smart farms, respectively. Respondents answered that improving awareness is the most important factor to introduce VSF. According to the statistical analysis, it was determined that education and promotion of the necessity of VSF would be important to diffuse the VSF.

Conclusion: VSF can be a solution to a variety of problems we face. The results of this study suggest a direction for the introduction and diffusion of VSF. In order to introduce VSF in the future, additional studies must be conducted on the legal system.

Keywords: green building, ICT, indoor smart farm, rooftop smart farm, urban farm

\section{Introduction}

The UN IPCC (Intergovernmental Panel on Climate Change) published the Special Report on Global Warming of $1.5^{\circ} \mathrm{C}$ (IPCC, 2018) and decided at the 48th Session of IPCC to limit global warming to $1.5^{\circ} \mathrm{C}$ by 2100 compared to before industrialization after consultation and approval of the international society (Korea Meteorological Administration, 2019). In this report, the IPCC is presenting channels to achieve carbon neutrality by 2050 worldwide and claiming the need for reformative change in the social system based on fossil fuels by 2030 (Korea Meteorological Administration, 2018). To support this, there is an urgent need to reduce greenhouse gases from energy, buildings, industries, and transport to 0 while maintaining economic growth by decoupling economic growth and fossil energy consumption, which must be promptly accompanied by development and application of various new technologies.

This study is based on the 'Policy Research for Supply and Expansion of Vertical Smart Farms' by Korea Institute of Machinery and Materials in 2019.

Received: March 19, 2021, Revised: March 31, 2021, Accepted: April 12, 2021

First author: Han Kyul Heo, hhk1042@gmail.com, (1) https://orcid.org/0000-0002-9849-9844

*Corresponding author: Eunseok Lee, enlee@auri.re.kr, (1) https://orcid.org/0000-0002-1735-7028 
Most agricultural products as food ingredients serve as a factor that adds to global warming by contributing to greenhouse gas emissions in transport as well as a vulnerable factor affected by the change of the crop ecosystem. In particular, the increase in the urban population has led to increased consumption of agricultural products in urban areas, which also gives rise to the import volume of agricultural products (Suh, 2012). Urban agriculture first began as weekend farms in the 1990s and is recently expanding into the social concept of reducing carbon footprints by producing agricultural products in the city and creating hobbies and jobs for urban residents (Lee, 2008; Lim, 2017; Leem, 2013; Kim et al., 2011). Rooftops, the typical unused spaces of the city, are used for urban agriculture along with abandoned lands (Lee, 2011; Jang, 2009; Lee, 2016). With the concept of the place established, the Act on Development and Support of Urban Agriculture is defining urban agriculture as the activities using land, buildings, or various living spaces in an urban area such as growing or cultivating crops, trees, or flowers, also including raising insects.

Smart technology in agriculture as an element of the Fourth Industrial Revolution is being developed in the form of smart farms that combined Internet of Things (IoT) and information and communications technology (ICT) with the conventional cultivation technology (Choe and Jang, 2019). Smart technology in buildings is developing toward the direction that can reduce greenhouse gas emissions effectively by applying new technologies to increase safety and energy efficiency (Lee et al., 2020). As smart farms and smart building technologies are combined with urban agriculture, they are introduced in Korea as new technologies that can contribute to reducing greenhouse gas emissions in buildings and transport and improving the vitality of urban residents (Lee, 2016). In particular, urban agricultural technology using rooftop greenhouses is receiving global attention as the next-generation innovative technology. This technology has diverse benefits proved by many studies, such as reduction of greenhouse gas emissions in the distribution process and retention of freshness as the city is the place of production and consumption for agricultural products (Sanjuan-Delmás et al., 2018; Piezer et al., 2019).

Accordingly, this study is conducted to investigate the physical characteristics of vertical smart farms and citizen awareness to adopt the new form of agriculture to the city as a response to climate change. To this end, this study first examined the physical building utilization methods of vertical smart farms and summarized in what form certain parts of buildings are used for vertical smart farms. Second, this study conducted a survey on citizen awareness about vertical smart farms and analyzed the key factors to adopt and expand them.

\section{Research Methods}

\section{Case studies on vertical smart farms in Korea and overseas}

\section{Theoretical background of vertical smart farms}

Smart farms are based on advanced science and technology. They maximize the production efficiency of crops by creating and managing the optimal growth environment for crops with the advancement of ICT (information and communications technology). The implementation of ICT enabled remote management of 1st generation smart farms, and $2^{\text {nd }}$ generation smart farms could reduce labor and maximize productivity with automatic control of farms.

The 1st generation smart farms completed based on the adoption of ICT and digitization merely increased convenience compared to traditional agriculture. The farms could be managed remotely, but people had to manage the settings and control of environment variables. The $2^{\text {nd }}$ generation smart farms applied the typical technologies of the Fourth Industrial Revolution such as big data and machine learning, thereby supporting decision making for optimal production of agricultural products.

Vertical smart farms, which first began with the concept of vertical farms that use each floor of a building as farmland, take the form that combined the use of buildings for vertical farms with the ICT-based agricultural technology of smart farms. The benefit of vertical smart farms is that buildings in the city can be used for farming, making this a suitable form of agriculture in Korea considering the ratio of urban residents exceeding 50\% and the decreasing rural population. In other words, vertical smart farms can consid- 
erably reduce labor for crop production and guarantee increased output compared to area.

\section{Case study method}

Search was conducted based on the following standard to collect cases of vertical smart farms. First, keywords such as 'building', 'farm', 'smart farm', 'vertical farm', 'structure', 'indoor farming', etc. were combined and searched on Google and Naver. We limited the results to cases in which farming was done in the form of smart farms using ICT and also using indoor and outdoor spaces of buildings. Through the second process, we excluded cases that are not included in the scope of our research, such as rooftop farming that lack the conditions of smart farms while using indoor and outdoor spaces of buildings, or agriculture carried out in the form of smart farms but take place in subway stations.

Case studies were conducted with focus on space utilization methods of vertical smart farms. Legal standards may vary depending on whether the indoor or outdoor space of a building is used, and consumer preferences may vary depending on the location of crop production. A pre-survey was conducted to examine where vertical smart farms actually take place.

Accordingly, this study classified the cases of vertical smart farms by utilization type of building space. Vertical smart farms can be classified by type of space into the type that uses parts of a building and the type that uses the whole building (Jin et al., 2018). This study reviewed whether vertical smart farms can be classified into these three types and examined additional types.

\section{Survey on perception of necessity of vertical smart farms in the city}

\section{Survey plan}

This study was conducted to identify the citizen awareness of vertical smart farms. Citizens are actual consumers of crops produced in vertical smart farms as well as the main agent to conduct the business. Accordingly, conducting a survey on their awareness will help come up with what is necessary for the development of vertical smart farms. In particular, by surveying the intention to purchase
Table 1. Questionnaire survey overview

\begin{tabular}{cc}
\hline Survey group & Citizens of Seoul and 6 metropolitan cities \\
\hline Survey method & Online survey \\
Sample size & 626 people \\
Survey period & October 8 to 14,2019 \\
\hline
\end{tabular}

or preferences of citizens by type of vertical smart farms derived from the case studies, it will be possible to obtain cues as to in which form vertical smart farms must be implemented in the future.

The survey was comprised of total 26 items on the awareness and necessity of vertical smart farms, intention to purchase agricultural products produced in vertical smart farms and the differences depending on space utilization form, and what is necessary for settlement of vertical smart farms. The respondents were general citizens of South Korea living in Seoul and 6 metropolitan cities such as Busan, Daegu, Incheon, Gwangju, Daejeon, and Ulsan. The sample size was 626 and the maximum margin of error was $\pm 3.91 \%$ p at the $95 \%$ confidence level. The survey was conducted online for 7 days from October 8 to 14, 2019 (Table 1).

The survey was comprised of total five parts. The first part was to select those living in Seoul and 6 metropolitan cities. The second part was the general awareness survey asking the respondents to rate their awareness of urban agriculture, smart farms, and vertical smart farms on a 4-point scale and their perception of necessity of each on a 5-point scale. The third part was to examine the respondents' buying behavior of agricultural products by asking where they purchase agricultural products and their intention to purchase agricultural products produced in vertical smart farms. The fourth part was related to policies for supply of vertical smart farms, asking about their thoughts on government support as well as the intention to participate in investment. The final part was on the characteristics of the respondents, asking about their rural migration plans, occupations, residential types, income, etc.

\section{Correlation analysis among survey items}

We conducted correlation analysis among awareness, necessity, agricultural products intention to purchase, percep- 
tion of necessity of government support, and intention to invest, excluding urban agriculture and smart farms and limiting the scope to vertical smart farms. Correlation analysis is used to analyze whether two variables have a linear correlation or not, and the correlation can be determined by obtaining the correlation coefficient. If the correlation coefficient is close to 0 , the correlation is low; if it is close to 1 , there is a high positive correlation; and if it is close to -1 , there is a high negative correlation. The correlation analysis was conducted using $\mathrm{R}$ software.

\section{Results and Discussion}

\section{Case studies on vertical smart farms in Korea and overseas}

\section{Rooftop smart farms}

Rooftop smart farms are a developed form of urban agriculture using rooftops. WISE Farm by KIMM is a smart farm installed by Korea Institute of Machinery and Materials using building rooftops. It uses sunlight, which is the benefit of using a rooftop, and takes the form of a green farming model by also using the emissions of gas engine driven heat pumps (Table 2).

Tour Montparnasse in Paris, France will install a rooftop smart farm when renovating the tower. Tour Montparnasse is one of the famous buildings in Paris, and a $17 \mathrm{~m}$ building will be added to the rooftop as a smart farm, and solar panels will be installed on the greenhouse.

\section{Façade smart farms}

There are not many cases in which façades are used. Pasona $\mathrm{O}_{2}$ in Tokyo, Japan uses both the indoor space and outer walls of the building (Table 2). The crops grown there are used as food ingredients at the cafeteria, emphasizing 'zero food mileage' that reduces both the transportation costs and energy use. However, Pasona $\mathrm{O}_{2}$ is also mostly using indoor space, while the outer walls are merely

Table 2. Case of vertical smart farms

\begin{tabular}{|c|c|c|c|c|}
\hline Division & Name & Picture & Characteristics & Source \\
\hline \multirow{2}{*}{\multicolumn{2}{|c|}{$\begin{array}{l}\text { KIMM wise } \\
\text { farm }\end{array}$}} & & $\begin{array}{l}\text { - Use rooftop space } \\
\text { - Use existing building } \\
\text { - Gas heat pump system is applied } \\
\text { for temperature control }\end{array}$ & $\begin{array}{l}\text { Blog of Korea } \\
\text { Institute of } \\
\text { Machinery \& } \\
\text { Materials }\end{array}$ \\
\hline & & & & \\
\hline & $\begin{array}{l}\text { Tour } \\
\text { Montparnass } \\
\text { e rooftop } \\
\text { greenhouse }\end{array}$ & & $\begin{array}{l}\text { - Rooftop smart farm was planned } \\
\text { during the renovation process } \\
\text { - A } 17 \mathrm{~m} \text { high greenhouse is added on } \\
\text { the rooftop. }\end{array}$ & $\begin{array}{c}\text { Home page of } \\
\text { igrow }\end{array}$ \\
\hline Facade & $\begin{array}{l}\text { Pasona } \mathrm{O}_{2} \\
\text { vertical urban } \\
\text { farm }\end{array}$ & & $\begin{array}{l}\text { - The outer wall focuses on flower } \\
\text { cultivation } \\
\text { - Smart farms are also operated in } \\
\text { indoor snaces }\end{array}$ & $\begin{array}{c}\text { Home page of } \\
\text { Pasona } \mathrm{O}_{2}\end{array}$ \\
\hline
\end{tabular}


Table 2. (continued)

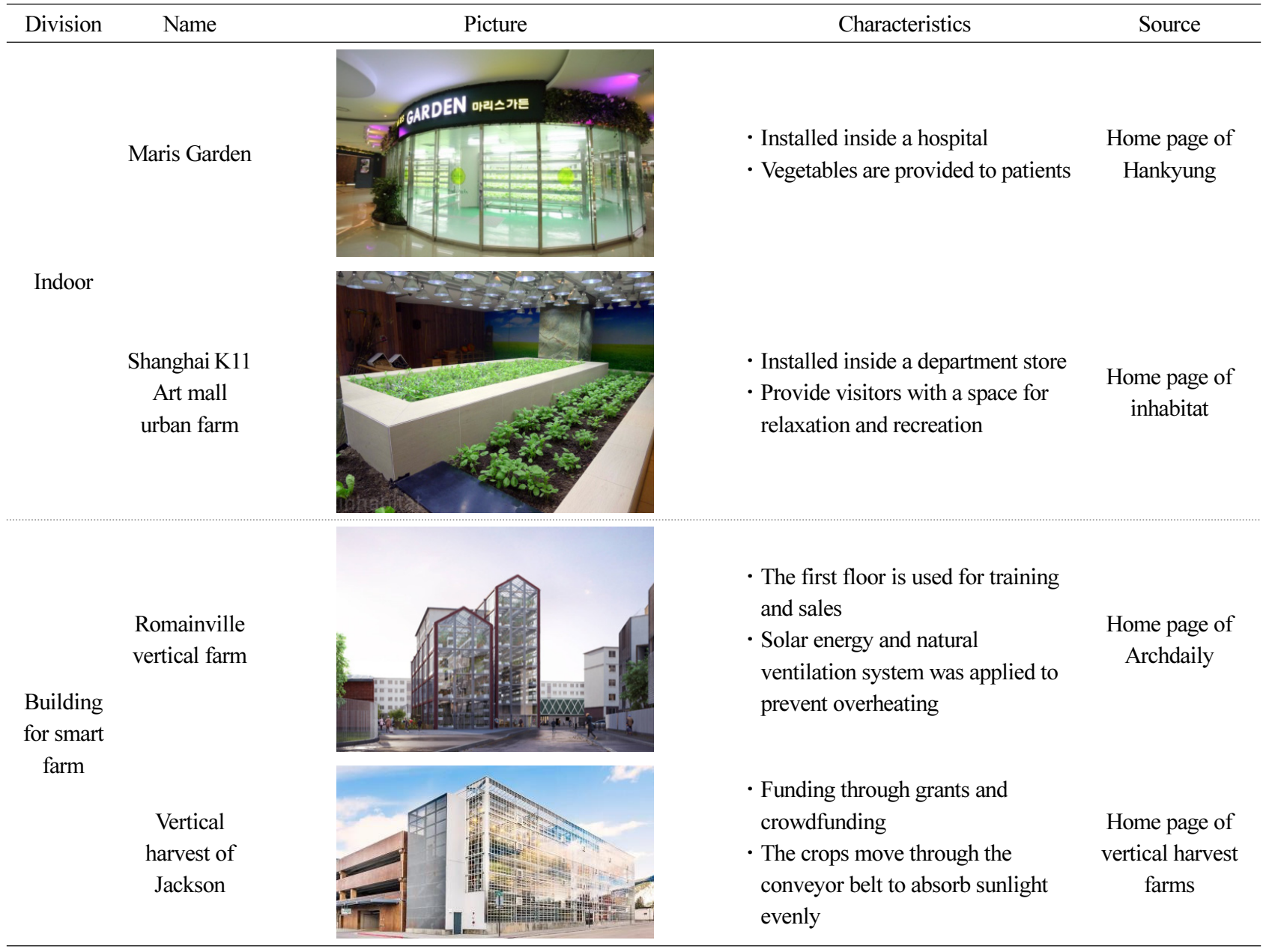

used to improve the view with flowers.

\section{Indoor smart farms}

Indoor smart farms are made by remodeling parts of indoor space in a building for farming. Maris Garden in Incheon and K11 Art Mall Urban Farm in Shanghai are farms using indoor spaces of buildings (Table 2). Maris Garden is located in the International St. Mary's Hospital in Incheon and supplies vegetables grown in the hospital to the patients. Culture medium is used in the form of a plant factor to cultivate crops, which enables safe food production free from pollution and soil water contamination. K11 Art Mall Urban Farm in Shanghai is located in a shopping mall and provides opportunities for shoppers to rest and participate in farming. Conditions for indoor plant growth are provided by using LED lighting and the automatic irrigation system. K11 Art Mall Urban Farm in
Shanghai also has livestock farming indoors unlike other smart farms.

\section{Smart farms using the whole building}

Smart farms using the whole building use the inside of the building as well as the entire building for agricultural activities. The vertical farm in Romainville, France is a smart farm using the whole building (Table 2). It has a rainwater management and storage system inside, and has a competitive edge in terms of energy efficiency by applying solar energy and a natural ventilation system. Vertical Harvest of Jackson in Wyoming, USA is a facility that is currently in operation. It has a three-story greenhouse structure, and the agricultural products produced there are sold in restaurants in three states. A conveyor belt is installed inside the greenhouse to facilitate mobility of crops. This enables all crops to absorb natural light equally, while 
also increasing space utility by obtaining locational convenience in crop harvest.

\section{Survey results on perception of necessity of vertical smart farms in the city}

A survey was conducted to collect responses of total 626 respondents living in Seoul and 6 metropolitan cities,

Table 3. Respondents' characteristics

\begin{tabular}{ccc}
\hline Region & Number of people & Ratio (\%) \\
\hline Seoul & 167 & 26.7 \\
Busan & 94 & 15.0 \\
Daegu & 82 & 13.1 \\
Incheon & 91 & 14.5 \\
Gwangju & 66 & 10.5 \\
Daejeon & 67 & 10.7 \\
Ulsan & 59 & 9.4 \\
Sum & 626 & 100 \\
\hline
\end{tabular}

and the number of respondents by region is as shown in the following table (Table 3). Seoul showed the highest ratio of respondents $(26.7 \%)$, and Ulsan the lowest $(9.4 \%)$.

\section{Awareness and necessity of vertical smart farms}

We surveyed the awareness of urban agriculture, smart farms, and vertical smart farms among the respondents. $29.2 \%$ responded that they know urban agriculture, $27.8 \%$ that they know smart farms, and $22.2 \%$ that they know vertical smart farms, while $43.5 \%$ responded that they do not know anything about vertical smart farms (Fig. 1).

The survey results on the necessity of urban agriculture, smart farms, and vertical smart farms are as follows. Citizens think that smart farms $(74.8 \%)$, urban agriculture $(69 \%)$, and vertical smart farms $(62.6 \%)$ to secure food resources (Fig. 2). More than $60 \%$ of the respondents think that all three types of farming are necessary.

The survey results on awareness and necessity show that
URBAN AGRICULTURE

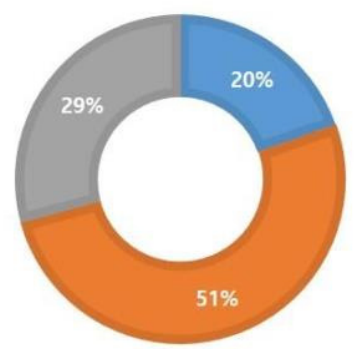

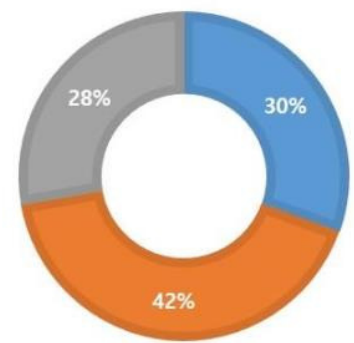

VERTICAL SMART FARM

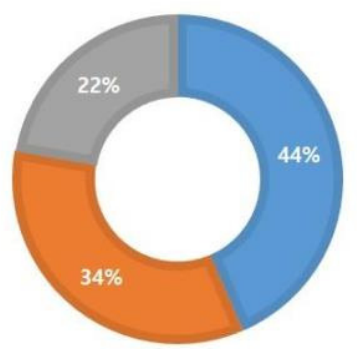

- Know $\quad$ Have heard of Don't know

Fig. 1. Awareness of urban agriculture, smart farm, and vertical smart farm.

URBAN AGRICULTURE

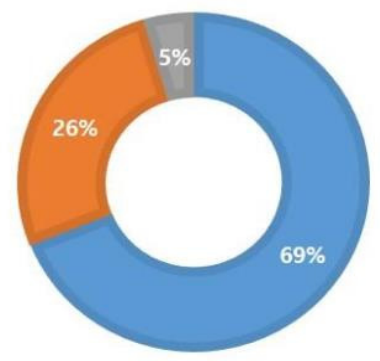

very Moderately
SMART FARM

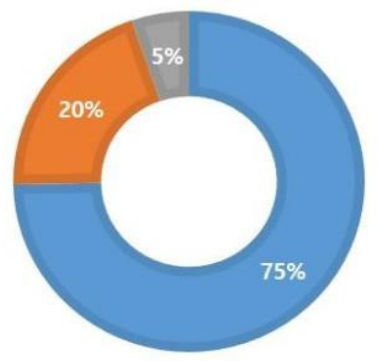

VERTICAL SMART FARM

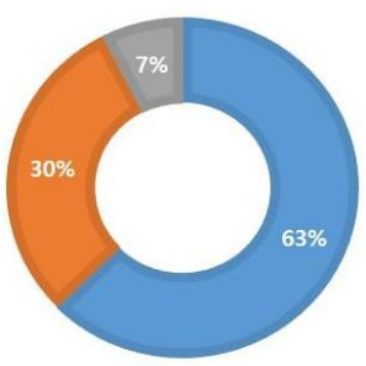

Fig. 2. Degree of awareness of the necessity for urban agriculture, smart farm, and vertical smart farm. 


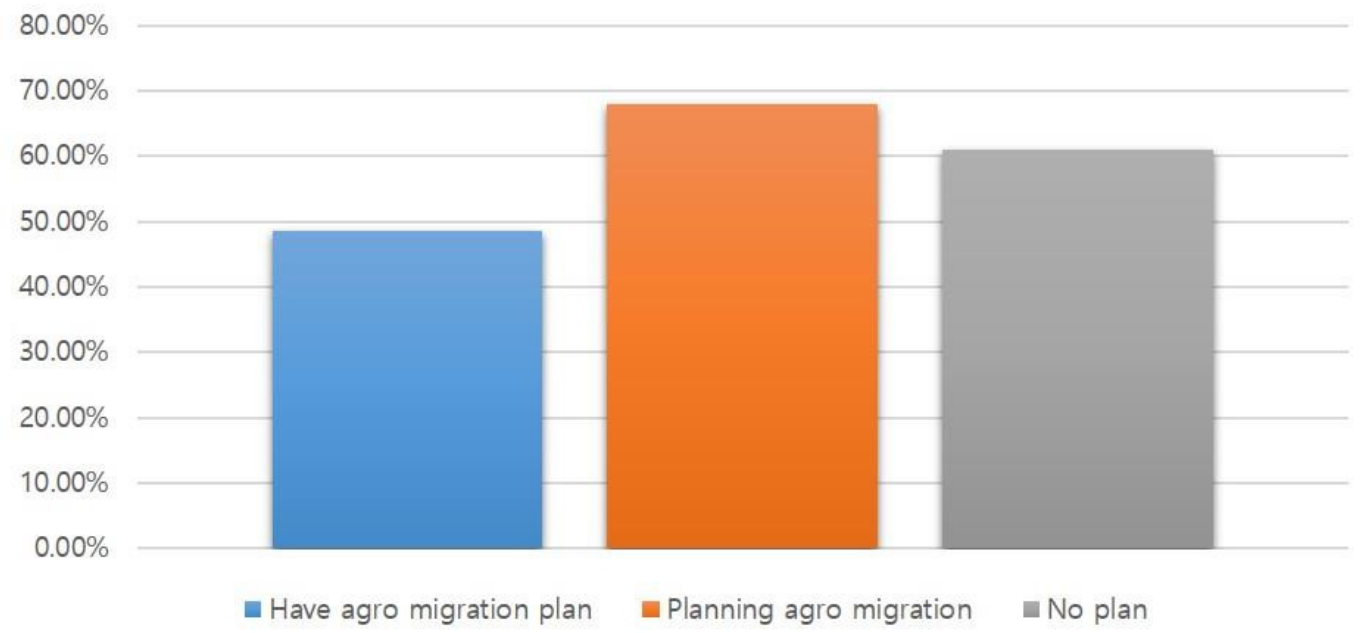

Fig. 3. Percentage of perceived necessity on vertical smart farm according to agro migration plan.

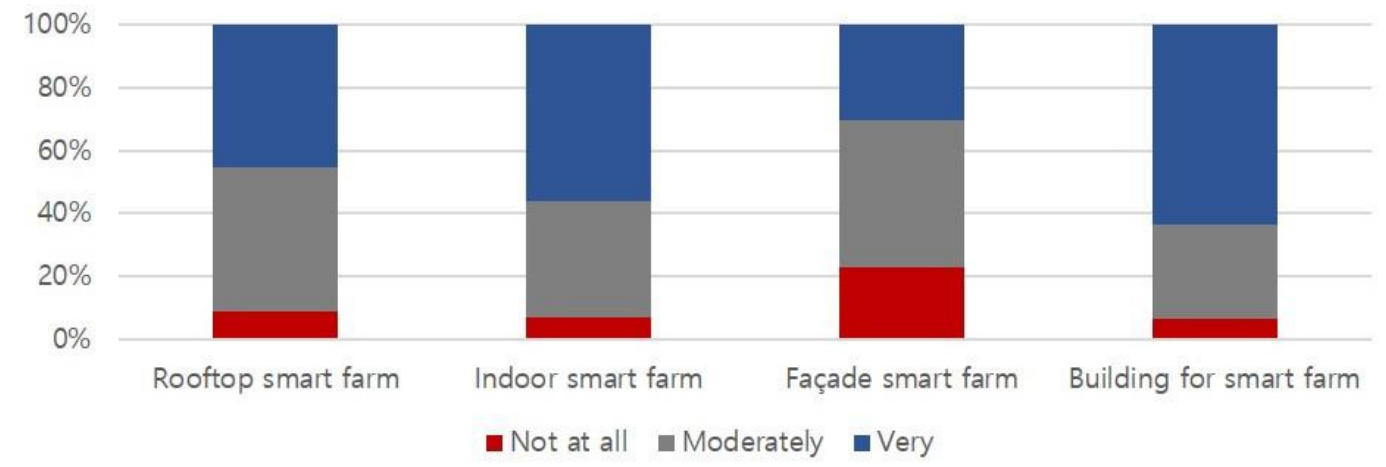

Fig. 4. Intention to purchase by production location.

smart farms showed a higher ratio of necessity than awareness in order to secure food resources. However, the necessity of vertical smart farms was still considered low. Moreover, the necessity of vertical smart farms showed certain reservations with many responding 'moderately'. This indicates that many respondents lack awareness of vertical smart farms.

Rural migration intention turned out to have an effect on perception of necessity of vertical smart farms (Fig. 3). $48.5 \%$ of those with rural migration plans, $68 \%$ of those considering rural migration, and $60.9 \%$ of those without rural migration plans felt that vertical smart farms are necessary. The respondents with rural migration plans felt the lowest need for vertical smart farms, while those considering rural migration felt the highest need. This is because those who already have plans to leave the city feel lower need for vertical smart farms that have high utility in the city. On the other hand, those considering rural migration were feeling higher need because vertical smart farms can be implemented near the city where they live.

\section{Intention to purchase agricultural products produced in vertical smart farms}

Case studies on types of vertical smart farms showed that there were rooftop farms, indoor farms, façade farms, and farms using the whole building. As a result of surveying the intention to purchase agricultural products produced in each type of the smart farms, it was found that the intention to purchase was highest in smart farms using the whole building (63.4\%), followed by indoor smart farms $(55.9 \%)$, rooftop smart farms $(45.2 \%)$, and façade smart farms (30.5\%) (Fig. 4).

The survey results proved that citizens showed higher intention to purchase crops produced indoors than crops 


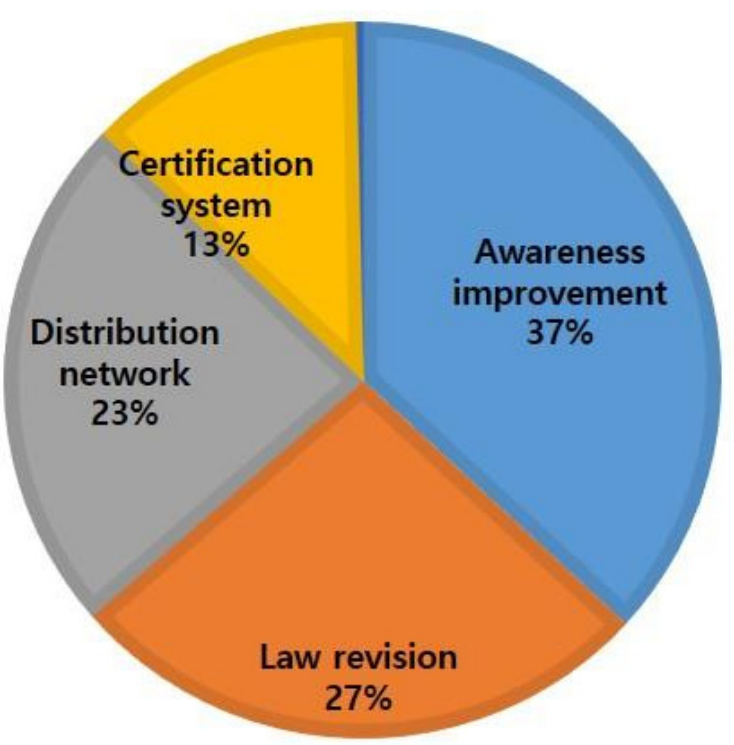

Fig. 5. Answers to 'What is the most necessary thing to introduce a smart farm'.

produced outdoors. In particular, façade smart farms showed not only low intention to purchase among the four types but also a high ratio of 'no intention to purchase' at $22.7 \%$, which is much higher than other types at below $10 \%$.

\section{Prionities for settlement of vertical smart farms}

We asked the respondents what they think is important for supply and settlement of vertical smart farms. The survey provided five examples of 'establishing/revising related laws', 'improving awareness of vertical smart farms', 'securing the distribution network for products', 'establishing a certification system', and 'others', asking the respondents to choose the first and second choice of answers they consider most necessary.

Most respondents chose 'improving awareness of vertical smart farms' as the first choice (36.9\%), followed by 'establishing / revising related laws' (26.7\%), 'securing the distribution network for products' (23.5\%), 'establishing a certification system' (12.6\%), and 'others' (0.3\%) (Fig. 5). When the first and second choices are added, the most frequently selected item was 'improving awareness of vertical smart farms' $(58.8 \%)$, which was the same as before, but the second choice was 'securing the distribution network for products' $(23.5 \%)$.

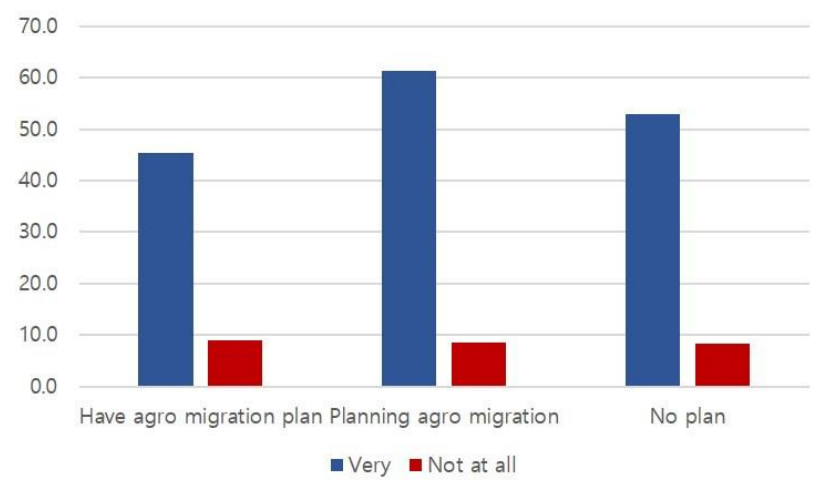

Fig. 6. Percentage of perceived necessity on government support according to agro migration plan.

\section{Awareness of govemment support and intention to invest}

$55.4 \%$ of the respondents said government support is necessary to boost vertical smart farm business, and 8.4\% said it is not. $45.5 \%$ of the respondents with rural migration plans said government support was necessary, which was lower than those considering rural migration (61.3\%) and those without rural migration plans (53\%) (Fig. 6). In other words, those who already have plans to leave the city did not feel much need for government support. On the other hand, those considering rural migration were anticipating government support for vertical smart farms so that farming can be done in the city.

As a result of asking whether citizens have intention to invest in vertical smart farms, $24.9 \%$ responded that they have intention to invest, $27 \%$ responded that they have no intention to invest, and $48.1 \%$ said they may or may not. Intention to invest according to rural migration plans showed a similar pattern with perception of necessity of government support. $37.7 \%$ of those considering rural migration had intention to invest in vertical smart farms, and $33.4 \%$ of those planning on rural migration had intention, indicating that the former had higher intention to invest.

\section{Correlation analysis among survey items}

The correlation analysis showed significant results in 5 items: awareness of vertical smart farms, perception of necessity, intention to purchase agricultural products produced in vertical smart farms, perception of necessity of government support for vertical smart farms, and individual 
Table 4. Result of the correlation analysis

\begin{tabular}{|c|c|c|c|c|c|}
\hline $\begin{array}{c}\text { Pearson } \\
\text { correlation }\end{array}$ & $\begin{array}{c}\text { Awareness of vertical } \\
\text { smart farm }\end{array}$ & $\begin{array}{c}\text { Awareness to } \\
\text { necessity }\end{array}$ & $\begin{array}{l}\text { Intention to } \\
\text { purchase }\end{array}$ & $\begin{array}{l}\text { Government } \\
\text { support }\end{array}$ & $\begin{array}{l}\text { Intention to } \\
\text { investment }\end{array}$ \\
\hline \multirow{2}{*}{$\begin{array}{c}\text { Awareness of } \\
\text { vertical smart farm }\end{array}$} & \multirow{2}{*}{1} & $.249^{* *}$ & $.162^{* *}$ & $.131^{* *}$ & $.328^{* *}$ \\
\hline & & .000 & .000 & .001 & .000 \\
\hline \multirow{2}{*}{$\begin{array}{l}\text { Awareness to } \\
\text { necessity }\end{array}$} & $.249^{* *}$ & \multirow{2}{*}{1} & $.526^{* *}$ & $.443^{* *}$ & $.360^{* * *}$ \\
\hline & .000 & & .000 & .000 & .000 \\
\hline \multirow{2}{*}{$\begin{array}{l}\text { Intention to } \\
\text { purchase }\end{array}$} & $.162^{* *}$ & $.526^{* *}$ & \multirow{2}{*}{1} & $.500^{* *}$ & $.444^{* *}$ \\
\hline & .000 & .000 & & .000 & .000 \\
\hline \multirow{2}{*}{$\begin{array}{c}\text { Government } \\
\text { support }\end{array}$} & $.131^{* *}$ & $.443^{* *}$ & $.500^{* *}$ & \multirow{2}{*}{1} & $.435^{* *}$ \\
\hline & .001 & .000 & .000 & & .000 \\
\hline \multirow{2}{*}{$\begin{array}{l}\text { Intention to } \\
\text { investment }\end{array}$} & $.328^{* * *}$ & $.360^{* *}$ & $.444^{* *}$ & $.435^{* *}$ & \multirow{2}{*}{1} \\
\hline & .000 & .000 & .000 & .000 & \\
\hline
\end{tabular}

${ }^{* *}$. Correlation is significant at the 0.01 level (2-tailed).

intention to invest. The results of the correlation analysis are as shown in Table 4.

Awareness of vertical smart farms showed a relatively low correlation with other items. The item with the highest correlation was intention to invest with the correlation of 0.328 , and with other items, the correlation was below 0.25 . In other words, high awareness of vertical smart farms does not necessarily mean that the respondents consider vertical smart farms as necessary, and high awareness also does not mean that they have high intention to purchase or perception of necessity of government support.

Necessity showed a relatively high correlation with other items unlike awareness. Necessity showed a correlation of $0.526,0.443$, and 0.360 , respectively, with intention to purchase, government support, and intention to invest. In particular, those thinking that vertical smart farms have high necessity tended to show high intention to purchase crops produced in vertical smart farms, which is contrary to the correlation of awareness and intention to purchase (0.162).

The correlation coefficients of intention to purchase and perception of necessity of government support, intention to purchase and intention to invest, perception of necessity of government support were all between 0.4 and 0.5 . Higher intention to purchase led to higher perception of necessity of government support and higher intention to invest, and higher perception of necessity of government support led to higher intention to invest.

The awareness and perception of necessity of vertical smart farms showed a similar pattern in the individual survey but a different pattern in the correlation analysis. Perception of necessity of vertical smart farms showed a moderate correlation around 0.5 with intention to purchase and perception of necessity of government support, whereas a very weak correlation around 0.15 was found in awareness of vertical smart farms. The correlation with intention to invest was 0.328 for awareness and 0.360 for perception of necessity, indicating that it was relatively high in perception of necessity.

In other words, considering that the factors to help expand use of vertical smart farms are government support for vertical smart farms and investment by general citizens, education and publicity about the necessity of vertical smart farms are important.

\section{Conclusion}

This study examined the types of vertical smart farms and conducted a survey on citizen awareness based on the above. Vertical smart farms could be classified into four types such as rooftop farms, façade farms, indoor farms, and buildings for smart farms. Considering the possibility of actual commercialization, there would be many difficulties in using the façades, and citizens also showed low intention to purchase crops produced on the façades.

The survey results showed that citizen awareness of ver- 
tical smart farms was low compared to that of urban agriculture or smart farms. Awareness of vertical smart farms was relatively high among those with rural migration intention who have knowledge in agriculture. Moreover, improving awareness of vertical smart farms was selected as something that is necessary first to settle vertical smart farms. In other words, it is necessary to improve the awareness and perception of vertical smart farms in order to implement them.

On the other hand, it was more important to improve perception of necessity rather than the awareness of the farms itself in order to raise funds to expand vertical smart farms. Intention to purchase, necessity of government support, intention to invest, and perception of necessity of vertical smart farms all had a higher correlation than the correlation with awareness. In other words, it is important to improve perception of necessity of vertical smart farms through education and publicity to introduce and expand vertical smart farms.

\section{References}

Choe, Y.C. and I.H. Jang. 2019. Smart farm in the era of the 4th industrial revolution. IN. 36(3):9-16.

IPCC. 2018. Special report; global warming of $1.5^{\circ} \mathrm{C}$. In Press. Retrieved from www.ipcc.ch

Jang, D.H. 2009. Policy implication for improving urban agriculture. J. Ind. Econ. Bus. 22(2):979-994.

Jin, D.R., Y.H. Kim, and H.M. Park. 2018. Case study of vertical farms using Japanese buildings. Korea Inst. Ecol. Archit. Environ. 18(1):47-56.

Korea Meteorological Administration. 2019. The 48th IPCC general assembly white paper. Retrieved from www. climate.go.kr

Korea Meteorological Administration. 2018. Main content of global warming of $1.5^{\circ} \mathrm{C}$. Retrieved from www. climate.go.kr
Kim, H.D., Y.D. Kwon, and Y.S. Kim. 2011. Gyeongnam urban agriculture status and development plan. Gyeongnam Institute. Retrieved from www.gndi.re.kr

Lee, Y.J. 2008. Farm building in Manhattan, New York? A re-focusing of urban agriculture. Gyeonggi research institute. Retrieved from www.gri.re.kr

Lee, Y.J. 2011. Urban agriculture promotion plan in Gyeonggido. Gyeonggi research institute. Policy Brief.

Lee, C.W. 2016. Overseas urban agriculture, focusing on Europe and the United States. Urban Aff. 51(572): 54-57.

Lee, E.S., S.N. Park, S.W. Nam. Ji, S.H. 2020. An improvement direction for the building certification based on the smart building concept, Architecture \& Urban Research Institute. Retrieved from www.auri.re.kr

Lim, J.E. 2017. A research on the formulation of social network of the vulnerable group through community garden. Doctoral dissertation, Seoul national university, Korea.

Leem, W.R., B.H. Koo. 2013. A study on the effects of education program on urban agriculture activation. J. Korean Soc. People Plants Environ. 16(6):119-123. https://doi.org/10.11628/ksppe.2013.16.6.463

Suh, K.W. 2012. An Analysis of Food Miles and $\mathrm{CO}_{2}$ Emission of Major Agricultural Products. J. Korean Soc. Atmos. Environ. 28(6):706-713. http://doi.org/10.5572/ KOSAE.2012.28.6.706

Sanjuan-Delmás, D., Llorach-Massana, P., Nadal, A., ErcillaMontserrat, M., Muñoz, P., Montero, J. I., Josa, A., Gabarrell, X., Rieradevall, J. 2018. Environmental assessment of an integrated rooftop greenhouse for food production in cities. J. Clean. Prod. 177(10):326-337. https://doi.org/10.1016/j.jclepro.2017.12.147

Piezer, K., Petit-Boix, A., Sanjuan-Delmás, D., Briese, E., Celik, I., Rieradevall, J., Gabarrell, X., Josa, A., Apul, D. 2019. Ecological network analysis of growing tomatoes in an urban rooftop greenhouse. Sci. Total Environ. 651(1):1495-1504. https://doi.org/10.1016/j.scitotenv.2018. 09.293 